\title{
Urodimento
}

REVISTA DE ESTUDOS EM ARTES CÊNICAS

E-ISSN 2358.6958

\section{A Nova Mulher: Inquietações masculinas e burlas femininas no cabaré berlinense}

\author{
Lívia Sudare de Oliveira
}

Para citar este artigo:

OLIVEIRA, Lívia Sudare de. A Nova Mulher: Inquietações masculinas e burlas femininas no cabaré berlinense. Urdimento - Revista de Estudos em Artes Cênicas, Florianópolis, v. 2, n. 41, set. 2021.

doi DOI: http:/dx.doi.org/10.5965/1414573102412021e0105

Este artigo passou pelo Plagiarism Detection Software | iThenticate 


\title{
Resumo
}

A Nova Mulher foi um fenômeno complexo, multidimensional, heterogêneo e gradual que alcançou expressão na Alemanha durante a República de Weimar. O direito à participação feminina na política, garantido pela Constituição de 1919 e o afluxo de mulheres no mercado de trabalho geraram tensões masculinas acerca dos papéis de gênero. O cabaré, enquanto um gênero comentador de seu tempo, trouxe para a cena as ansiedades geradas pela Nova Mulher, representando-a através de tipificações. Este artigo pretende analisar algumas destas tipificações - indício das inquietações masculinas - em contraponto às estratégias femininas para burlá-las.

Palavras-chave: Nova Mulher. Cabaré. Tipificações. República de Weimar.

\section{The New Woman: Male anxieties and female circumvention in Berlin cabaret}

\begin{abstract}
The New Woman was a complex, multidimensional, heterogeneous and gradual phenomenon that gained strength in Germany during the Weimar Republic. The right to female participation in politics guaranteed by the 1919 Constitution and the influx of women in the labor market generated male tensions about gender roles. Cabaret worked as a commentator of its time and shed light on the masculine anxieties regarding the New Woman, representing them through typifications. This article intends to analyze some of these typifications - evidence of male concerns - in counterpoint to female strategies to circumvent them.
\end{abstract}

Keywords: New Woman. Cabaret. Typifications. Weimar Republic.

\section{La Nueva Mujer: Ansiedades masculinas y elusión femenina en el cabaret de Berlín}

\section{Resumen}

La Nueva Mujer fue un fenómeno complejo, multidimensional, heterogéneo y gradual que ganó fuerza en Alemania durante la República de Weimar. El derecho a la participación femenina en la política garantizado por la Constitución de 1919 y la afluencia de mujeres al mercado laboral generaron tensiones masculinas sobre los roles de género. Cabaret trabajó como comentarista de su época y arrojó luz sobre las ansiedades masculinas con respecto a la Nueva Mujer, representándolas a través de tipificaciones. Este artículo pretende analizar algunas de estas tipificaciones - evidencia de las preocupaciones masculinas - en contrapunto a las estrategias femeninas para eludirlas.

Palabras clave: Nueva Mujer. Cabaret. Tipificaciones. República de Weimar.

${ }^{1}$ Doutora em Teatro pelo Programa de Pós Graduação em Teatro da Universidade do Estado de Santa Catarina (UDESC), Mestre em Teatro pelo mesmo programa, Graduação em Educação Artística com habilitação em Artes Cênicas pela UDESC. Bacharel em Direito pela Universidade do Sul de Santa Catarina. Professora doutora da Universidade Federal da Bahia (UFBA). Lisudare@gmail.com

(9) http://lattes.cnpq.br/5032876738236851 (D) http://orcid.org/0000-0002-7750-5125 
A fórmula do cabaré é o golpe final para aqueles obstáculos que impediram as mulheres de serem as protagonistas originais, corajosas, confiantes, alegres e engraçadas que se tornaram. Em cena entra uma "ela" implacável em fazer autoironia, sabe fazer rir de si mesma e também dos outros. Se acendem os refletores sobre os complexos e limites do sexo oposto, ela zomba da sociedade e das suas contradições [...]. (Delfina Ducci)

Nos hinos homéricos, mais precisamente naquele identificado pelo número vinte e cinco, há uma homenagem ao deus Apolo e às musas. Canonicamente, o deus grego andava na companhia de nove musas². Responsáveis pela inspiração humana, cada uma dessas divindades estava responsável por um aspecto do conhecimento artístico e/ou científico. Em 1920 Jean Cocteau ${ }^{3}$ proclamou o cinema como a décima musa a quem a diretora Lotte Reiniger ${ }^{4}$ batizou de "Cinoterpe". Contrapondo-se às declarações de Cocteau, o cabaretista alemão Edmund $\mathrm{Nick}^{5}$, para quem a décima musa era, de fato, o cabaré, afirmava:

A décima musa é aquela senhora da comitiva de Apolo a quem foi confiado o patrocínio do cabaré. Ela não usa os longos peplos de suas irmãs mais sérias. [...]. É preciso imaginar a décima musa com os joelhos à mostra, maquiada com muito ruge nos lábios, sobrancelhas depiladas, linda, cheia de um atrevimento envolvente - para não dizer atrevido uma mulher que vira a cabeça dos mais sérios [...] (Nick apud Danielczyk, 2017 p.16).

A associação do cabaré à figura da mulher não foi apenas uma licença poética de Nick. A historiografia do gênero - Alan Laureau (1995), Lisa Appignanesi (1984), Peter Jelavich (1997), dentre outros - mostra que a participação feminina foi bastante expressiva, tanto como profissionais como quanto público. Diseusen, bailarinas, conferencistas, diretoras, donas de negócio, muitas foram as posições ocupadas por mulheres no universo cabareteiro. Katrin Sieg atribui essa presença

\footnotetext{
${ }^{2}$ Calíope, Clio, Érato, Euterpe, Melpômene, Polímnia, Terpsícore, Talia e Urânia.

3 Jean Cocteau (1889-1963) - encenador, ator, dramaturgo, poeta, romancista, designer e cineasta francês.

${ }^{4}$ Lotte Reiniger (1899-1981) - diretora de cinema alemã, pioneira na arte da animação de silhuetas.

${ }^{5}$ Edmund Nick (1891-1974) - compositor musical, crítico, diretor musical e cabaretista.
} 
à própria natureza do cabaré, pois o fato dele estar na encruzilhada entre

a experimentação artística, a agitação política e o entretenimento de massa, criou um ambiente único de produção cultural, especialmente para mulheres. Excluídas dos discursos sobre a arte erudita - seja ela mainstream ou avant-garde - elas puderam adentrar o universo artístico como participantes ativas através da porta dos fundos ${ }^{6}$ (Sieg, 1997, p.66).

A décima musa de Nick - maquiada, com os joelhos à mostra e dotada de uma personalidade atrevida - faz referência à Nova Mulher. Die neue Frau, the New Woman, la Nueva Mujer ou a Nova Mulher foi um fenômeno que teve seu início no final do século XIX na Inglaterra e que por volta da década de 1920 já havia alcançado expressão em países diversos, tais como França, China, Egito e Rússia. Na Alemanha ficou em evidência durante a República de Weimar (1918-1933), quando encarnou as tensões e ansiedades trazidas com as transformações sociais do pós-guerra e da instauração de um novo regime político. A capital do país, Berlim, era a materialização da modernidade e foi representada na literatura e nas artes pela figura de uma mulher sensual, livre e, muitas vezes, perigosa.

Segundo Carol Schmid, a Nova Mulher "se transformou em um símbolo de liberdade social feminina, moda e beleza, mas também da modernização da economia e de tensões político-sociais" (Schmid, 2014, p.5). O cabaré, gênero cuja principal fonte de matéria prima é a atualidade, explorou a questão da Neue Frau, retratando-a frequentemente em suas chansons ${ }^{7}$. As composições, em sua maioria feitas por homens, apresentam tipificações femininas construídas a partir do olhar masculino. Entre as diversas tipificações, a Neurótica Urbana ganha destaque, por se tratar de uma categoria ampla criada para representar o lado negativo da modernidade e pode ser entendida como um reflexo da Nova Mulher.

Outra tipificação bastante característica da cena cabareteira é a Prostituta, que, segundo Stephen Brockmann, (Brockmann apud Boak, 2013, p.274) transformou-se no símbolo da República de Weimar. De fato, são inúmeros os

\footnotetext{
${ }^{6}$ Termo referente ao cabaré.
}

Chanson é um estilo polifônico de canção ou música com versos repetidos que nasceu por volta de 1400 nas tabernas francesas. Foi muito utilizada como uma forma de registro e crítica do cotidiano. Fortalecida pelo uso da sátira, a chanson também foi utilizada como forma de protesto. Mais adiante neste artigo, o tema será debatido. 
livros, os filmes e as canções que abordam o assunto. Marlene Dietrich imortalizou o tipo no cinema em 1930, quando interpretou a personagem Lola-Lola no filme 0 Anjo Azul do diretor Josef von Sternberg. A obra de George Grosz está repleta de mulheres retratadas como prostitutas. A temática da prostituição e a representação de mulheres enquanto tal era tão presente no cotidiano de Weimar, que existe uma categoria de canções de cabaré, chamada Dirnenlied, que retrata a questão. Para Bernd Weddig (2001, p.211) a prostituta simboliza o impacto da hiperinflação, representando a "permissividade sexual somada à miséria econômica e social".

Este artigo parte da premissa de que as tipificações da Neurótica Urbana e da Prostituta são uma reação aos processos históricos vivenciados na Alemanha, mais especificamente à Nova Mulher, que surgiu ao final da 1a Guerra Mundial. Intenta-se então investigar $\theta$ este fenômeno e compreender como as chansons de cabaré, compostas a partir de um olhar masculino, apresentavam as tipificações mencionadas e de que forma as artistas esgarçavam as imposições do tipo, criando performances expandidas para além do discurso da canção.

Convém ressaltar que em virtude da bibliografia desta pesquisa contar com muitas fontes em língua estrangeira, a autora decidiu não colocar as citações em seus idiomas originais para não sobrecarregar o espaço das notas de rodapé. As traduções apresentadas ao longo do texto foram realizadas pela autora.

\section{A Diseuse como a imagem do cabaré}

A história do cabaré é atravessada pelas reflexões acerca do imaginário. Inúmeras são as associações imagéticas feitas à palavra "cabaré": um gato preto olhando desafiadoramente para quem the contempla ${ }^{8}$, pernas lançadas ao $\operatorname{ar}^{9}$ nos mais diferentes contextos, os olhos grandes de Liza Minelli semi ocultos sob seu chapéu $\operatorname{coco}^{10}$ ou ainda Marlene Dietrich vestida de terno e fumando um charuto.

\footnotetext{
${ }^{8}$ Como no pôster criado por Théophile Steinlen para o Chat Noir.

${ }^{9}$ Como pode ser visto nas pinturas de Toulouse Lautrec referentes ao Moulin Rouge.

${ }^{10}$ No filme Cabaret de 1972.
} 
Michel Maffesoli entende que as imagens são resultado de um imaginário, portanto, a existência deste "determina a existência de conjuntos de imagens" (Maffesoli, 2001, p.76). O imaginário, segundo o autor, transita pelo campo do racional ou do razoável, mas tem potencialidade para inserir-se também na esfera do imaginativo, do lúdico, do afetivo, dos sonhos, do onírico e pode abraçar também o irracional. Ele aponta ainda, que este "é, ao mesmo tempo, impalpável e real" (Maffesoli, 2001, p.77) e ultrapassa o indivíduo, impregnando o coletivo.

A descrição de Nick sobre a musa de cabaré aponta para uma associação do gênero com o feminino. Sandra Danielczyk (2017, p.8) acredita que o cabaretista foi inspirado pelo número expressivo de mulheres na cena cabareteira. Para além dos compositores e poetas, foram as mulheres, através de suas performances de canções e números de dança, que deram um rosto ao cabaré. Apesar da existência de diversos artistas de destaque, tais como Frank Wedekind, Curt Bois e Hugo Ball, a presença feminina foi numericamente mais proeminente. Segundo Danielczyck (2017, p.8), as mulheres eram o ponto focal do cabaré político-literário, do beer hall e do cabaré revista durante a República de Weimar. Eram principalmente elas que realizavam a mediação entre autor, compositor e público através da chanson.

Katrin Sieg (1997, p.68) aponta que os números de dança e de chansons eram o ponto central do cabaré, e as mulheres ganharam destaque em ambos gêneros. Nomes como Claire Waldoff e Margo Lion - na interpretação de canções -, Valeska Gert e Anita Berber - na dança-, ilustram bem essa observação. Diretoras como Rosa Valetti e Trude Hesterberg11 foram cruciais para a expansão e manutenção da cena artística de vanguarda de Berlim, pois foram fundadoras de dois importantes cabarés - Cabaret Größenwahn e o Die Wilde Bühne, respectivamente - pelos quais destacados artistas transitaram, incluindo Lion, Waldoff, Kate Kühl, Kurt Tucholsky, Friedrich Hollaender e Bertolt Brecht.

Para Sieg (idem) o cabaré oferecia às mulheres a oportunidade de tornaremse autoras e donas de seus processos artísticos de uma maneira impossível de alcançar na arte erudita. Tanto Sieg (1997) quanto Danielczyck (2017) reforçam a importância das Diseusen e das chansonniers para o cabaré. Ambas as autoras

${ }^{11}$ Atrizes e diseusen de grande sucesso no cabaré, no teatro e no cinema. 
concordam que o trabalho dessas artistas não pode ser entendido apenas como o de intérpretes do trabalho masculino, mas sim como a resultante de um processo criativo potente por si só.

Desde os primórdios do cabaré literário discute-se a respeito do termo correto para referenciar a presença de atrizes cantoras ${ }^{12} \mathrm{em}$ cena. Diseuse, Chanteuse, Chansonnière e Chansonette são alguns deles. O dicionário de cabaré Metzler Kabarett Lexicon de Klaus Budizinski e Reinhard Hippen adota Chansonnière como o termo comum usado na Alemanha para indicar "a pessoa que apresenta a chanson”. O verbete apresenta a definição de diversas funções que podem receber este nome,

Chansonnier, Chansonnière: - Termo comum utilizado na língua alemã para o/a apresentador de Chansons. No francês a palavra foi originalmente cunhada em referência ao cantor de Chanson no cabaré artístico. - Com o tempo, Chansonnier passou a fazer referência também ao artista de cabaré que em seu solo não necessariamente precisa cantar, mas que comenta de forma cômica os eventos cotidianos, sendo similar ao que em alemão é entendido como emcee (conferencista). Termo usado para referenciar um autor-intérprete que recita as letras para suas próprias músicas. - Termo usado para referenciar o autorintérprete-compositor que canta suas próprias músicas. O termo Chansoniere tem prevalecido sobre o termo Diseuse (Budizinski; Hippen, 1996, p.61).

A maioria dos termos utilizados faz referência à chanson, um estilo polifônico de canção com versos repetidos que nasceu por volta de 1400 nas tavernas francesas e foi muito utilizada como uma forma de registro e crítica do cotidiano. Fortalecida pelo uso da sátira, a chanson também foi utilizada como forma de protesto. Para Wolfgang Ruttkowski (2001, p.45), mais do que um tipo de música, a chanson de cabaré demanda uma performance intencional. Aristide Bruant, considerado o pai da chanson realiste e da chanson de cabaré, foi o pioneiro na técnica do chanteur, que consiste em cantar a letra de acordo com a melodia proposta, sem grandes quebras rítmicas como um cantor.

Em contraposição, há uma outra maneira de execução desenvolvida pela atriz e cantora Yvette Guilbert, contemporânea de Bruant. Guilbert foi a precursora da

${ }^{12} \mathrm{E}$ atores cantores também, alterando a grafia de acordo com o gênero. 
técnica da diseuse. De acordo com Ruttkowski (2001, p.46), a maneira como a artista apresentava suas canções foi definida por ela mesma como un drame condensé, um drama condensado em poucas falas. Suas performances envolviam um tipo de recitação desenvolvido por ela, a qual chamou de rythme fondu.

O que é rythme fondu? Foi a minha nova contribuição à arte da diseuse. Essa foi a minha descoberta de começo de carreira. Desde então, o mundo todo tem imitado. Essa descoberta consiste em abrir mão do ritmo musical, substituindo-o pela palavra rítmica de acordo com a acentuação e as necessidades do texto (Guilbert apud Ruttkowski, 2001, p.47).

Esta técnica de suspensão do ritmo envolvia o abandono temporário da métrica em detrimento da expressão e do conteúdo, abrindo espaço para a aceleração ou desaceleração das palavras, intercalando canto e fala. Ruttkowski (Guilbert apud Ruttkowski, 2001, p.47) aponta que os franceses utilizam alguns termos para diferenciar as técnicas de apresentação de canções. Chanteur e Chanteuse referem-se puramente ao/a intérprete. Chansonnier e Chansonnière são os/as executantes de suas próprias composições. Diseuse é a nomenclatura que deSiegna a/o artista que utiliza a técnica de Guilbert. Há ainda uma quarta denominação que é a Chansonette, do francês pequena canção, que foi apropriado erroneamente à língua alemã e fazia referência a uma apresentação puramente cantada. Yvette Guilbert, segundo Danielczyck (2017, p.20), fazia questão de usar a nomenclatura Diseuse, pois entendia que a sua arte era distinta daquela da intérprete propriamente dita. A francesa explicou a função da Diseuse da seguinte forma:

Fazer as palavras brilharem, apagá-las, imergi-las em luz e sombra, reforçá-las ou expô-las de acordo com seu Siegnificado. Em suma, inclui tudo que preenche um texto de vida, que o deixa desvanecer; que traz o texto à vida com força, cor, estilo, graça ou grosseria. E isso requer uma dicção especial: uso ativo do verbo, estruturação consciente do texto, desenho pictórico e plástico do mundo, ênfase na estrutura concisa e na exposição do Siegnificado implícito. A arte da atuação à serviço da cantora sem voz, mas que é capaz de deixar a orquestra ou o piano cantar em seu lugar. Essa é a minha arte (Guilbert apud Danielczyck, 2017, p.20).

Paradoxalmente, afirma Ruttkowski (2001, p.48), a técnica de Guilbert não 
conquistou tanto os artistas franceses, que preferiram o estilo de Bruant. Na Alemanha, porém, essa espécie de canto falado ganhou força não apenas pela qualidade de seus compositores e letristas, mas também por conta do aprimoramento das técnicas de performance. A partir da defesa que Guilbert faz a respeito da distinção de sua técnica, bem como da análise das outras definições, pode-se afirmar que para o contexto do cabaré alemão o uso da nomenclatura Diseuse e Diseur parece mais adequado. Ao falar sobre a influência da chanson de cabaré alemã na música e no teatro musical americano, William Farina aponta os diversos elementos que contribuíram para a consolidação dessa tradição

A distinta versão alemã, no entanto, que emergiu na humilhação do resultado da 1 a Guerra Mundial, foi o resultado da combinação entre o jazz americano, a dança burlesca, o standup comedy, o vaudeville grotesco e a performance arte provocadora, tudo isso amarrado por uma pesada (e às vezes letal) dose afiada de comentário político-social. Havia muitas canções de amor também, mas elas eram pouco convencionais (Farina, 2013, p.1).

Resta evidente que, em se tratando de chanson de cabaré, não se pode falar apenas de música e letra. Nos cabarés alemães a performance foi de extrema relevância para o sucesso do gênero. Nos Diálogos de Messingkauf, Brecht aponta que "Não se pode negligenciar o fato de que não é a peça mas sim a performance que é o verdadeiro propósito de todo o esforço" (Brecht, 1994, p.74). A relação de Brecht com o cabaré foi forte o suficiente para que, hoje, seja possível tomar essa afirmação também para esse contexto. Faz-se necessário, então, compreender a natureza dessa performance que não é regida pelas regras do papel dramático.

Christina Streva (2017, p.131) chama a atenção para o Paradoxo PersonagemPersona. Citando Alan Lareau (1995), Lisa Appignanesi (2004) e J.M Ritchie (1982), a pesquisadora demonstra que em se tratando de cabaré não é possível falar em um desenvolvimento de personagem propriamente dito, visto que as atrizes e atores entram e saem de diferentes personagens ao longo da performance. O trabalho da/do performer instaura um estado liminar (Turner, 2013) e opera com base no princípio da contradição. Oliver Double e Michael Wilson apontam que

Os performers de cabaré não costumam trabalhar representando 
personagens a partir de um realismo psicológico baseado na empatia e no emocionalismo, mas sim aparecendo sob o disfarce de seu 'eu de fora do palco' (ou uma persona baseado nisso) e dialogando com a audiência diretamente. Como Trude Hesterberg coloca, "O impacto das canções de cabaré advém principalmente da personalidade que a expressa" (Double; Wilson, 2006, p.50).

Energia, presença e carisma, são atributos apontados pela historiografia de cabaré como fundamentais para a popularidade do gênero. As/os performers de cabaré exploravam suas fisicalidades ao máximo. Uma voz ríspida, um corpo excessivamente alto, um rosto infantil, uma aura maternal, maneirismos; as Diseusen identificavam seus pontos de destaque, intensificando-os a partir das expectativas geradas pelo público e pelas tipificações sociais que estavam em voga na época. O que Double e Wilson chamam de persona não é uma representação de si mesma, mas pode ser entendida pelo que Renato Cohen (2002, p.54) chama de "máscara ritual". O que se vê na cena cabareteira é uma auto representação do eu como um contexto ${ }^{13}$. Como o cabaré atua na esfera do épico, a referência de si age apenas como um disparador, sendo a atualidade e o cotidiano - a moda, a política, a economia, a sexualidade, etc. - o combustível que alimenta a criação das performers.

\section{A Nova Mulher e a Prostituta nas chansons e na cena de cabaré}

No filme Cabaret de Bob Fosse (1972) a personagem Sally Bowles é retratada como uma jovem femme fatale americana que se muda para Berlim em busca do estrelato. Durante o dia transita pelos grandes estúdios de cinema em busca de um papel e durante a noite trabalha como performer no cabaré Kit Kat Club. Através das experiências eufóricas, frenéticas e às vezes ingênuas de Bowles, acompanhamos a agitação cultural da cidade, os impactos da modernidade e a ascensão do nazismo na Alemanha. A personagem, imortalizada por Liza Minnelli em uma performance que the rendeu o Oscar de Melhor Atriz, pode ser entendida como uma atualização de tipificações femininas criadas a partir das inquietações

${ }^{13}$ Self as a context que segundo Cohen (2002) é a maneira como os americanos chamam esse processo de autorepresentação. 
masculinas acerca do fenômeno da Nova Mulher.

Christopher Isherwood reuniu em Sally Bowles diversas características tipificadas já exploradas pela literatura e pelas canções de cabaré. Bowles surge do cruzamento de tipos femininos bastante consolidados, como a vamp, a girl e a femme fatale. A personagem foi inspirada pela breve passagem da atriz, jornalista e ativista política inglesa Jean Ross ${ }^{14}$ pela cena artística de Berlim no começo dos anos 30, quando ela tinha apenas 19 anos. Após este momento, Ross voltou para a Inglaterra, onde se filiou ao Partido Comunista da Grã-Bretanha. Foi correspondente internacional durante a Guerra Civil Espanhola e secretária geral da Liga dos Trabalhadores. Até a sua morte, em 1973, destacou-se como ferrenha opositora às armas nucleares, à Guerra do Vietnã e ao apartheid na África do Sul. Sua trajetória profissional e política, no entanto, ficou ofuscada pela força imagética Sally Bowles.

Segundo Sarah Caudwell (apud Mizejewski, 2014, p.44), filha de Ross, esta considerava que Sally Bowles ofendia suas convicções feministas, uma vez que a sua versão ficcionalizada fora construída em cima de uma convenção que determina que "uma mulher deve ser ou virtuosa (no sentido sexual) ou uma prostituta”. Durante a República de Weimar, a questão da distinção entre a prostituta e a mulher virtuosa gerou inúmeros debates e evidenciou as ansiedades masculinas em relação à mudança nos papéis de gênero. Katharina von Ankum explica que

A obsessão discursiva a respeito da identidade feminina foi incitada pela sexualização do espaço público, resultante da entrada de grandes números de mulheres no mercado de trabalho moderno, da percepção de que havia uma espécie de greve da maternidade entre as mulheres da classe média, e da decisiva aparência masculinizada da Nova Mulher que reprimia os marcadores físicos da feminilidade (Ankum, 1997, posição 88 de 3569).

A história do movimento das mulheres alemãs é marcada pela diversidade de reivindicações, associações e ideologias. Ainda no século XIX a criação de sindicatos de operárias e de associações de mulheres contribuiu para a mobilização feminina na luta por direitos. Segundo Angelika Schaser, independente 
de classe social ou "do quão diversa suas identidades e experiências individuais eram, as mulheres na Alemanha Imperial tinham uma coisa em comum: suas desvantagens legais, econômicas e políticas em relação à seus maridos” (Schaser, 2008, p.129). A busca por emancipação refletiu no aumento de reivindicação por educação e postos de trabalho.

Diante da perda de mão de obra masculina durante a 1a Guerra Mundial, as mulheres foram incorporadas aos esforços de guerra, ocupando postos que até então eram considerados domínios de homens. Para além do trabalho doméstico e nas fábricas, a mão de obra feminina foi utilizada na construção de estradas, expansão de metrô, em bancos e companhias de seguros, na indústria química, em escritórios governamentais e militares, territórios até então considerados masculinos. Escalas de trabalhos abusivas e ausência de respeito às leis trabalhistas referentes ao trabalho noturno conduziram muitas mulheres a uma carga de trabalho de mais de 60 horas por semana. Ainda de acordo com Richie:

\begin{abstract}
Muitas mulheres sofriam de tuberculose; a taxa de mortalidade entre jovens adultos entre os vinte e os vinte e nove anos cresceu de 32 para 10,000 em 1917; a maioria das vítimas eram mulheres que provavelmente já tinham a tuberculose latente desde a infância e que sucumbiram à doença devido à exaustão, subnutrição, frio e a má ventilação nas fábricas. Essa súbita inversão nos papéis foi subsequentemente combustível da luta pelos direitos iguais, mas na época essas oportunidades foram dadas às mulheres apenas pela falta de homens (Richie, 2013, posição 7308 de 31086).
\end{abstract}

Ao final do conflito, uma estimativa de quase dois milhões de homens haviam perecido em batalha. Como consequência da derrota, uma enorme mobilização popular tomou as ruas de Berlim e de outras cidades alemãs no dia 09 de novembro. Alimentados pelo sentimento de traição e ruína, a multidão destruiu os diversos símbolos associados à figura do Kaiser e a seu governo. Ante a pressão popular, o chanceler Max Von Baden passou o poder para os sociais democratas. A abdicação de Guilherme II veio logo em seguida, dando fim ao 2 o Reich. Começava, assim, a República de Weimar. A transição, de acordo com Anton Gill, foi cheia de dificuldades, e as consequências foram sentidas por anos.

Após a guerra, uma das tarefas mais difíceis para os líderes do que hoje 
é conhecido como república de Weimar era introduzir ideias democráticas para um povo arruinado e desiludido cujo instinto era se agarrar a valores que já conhecia: ordem, autoridade militar e governo por uma figura paterna - um instinto que irá ter consequências desastrosas quando Hitler se apresentar como o sucessor de Bismarck e Hindenburg (Gill, 2015, posição 2015 de 7935).

O novo regime demandou uma nova constituição federal. Foi graças a este instrumento jurídico que as mulheres conquistaram o direito à participação política ampla, que envolvia o voto e a candidatura a cargos públicos. Helen Boak (2013, p.89) afirma que em janeiro de 1919 trinta e sete mulheres - das trezentas e dez candidatas - foram eleitas para a assembleia nacional, e cento e dezessete mulheres assumiram o cargo de deputadas estaduais. Foi neste contexto de maior visibilidade e participação feminina na esfera pública que o fenômeno da Nova Mulher passou a ser amplamente discutido na Alemanha.

Essa Nova Mulher, cuja vida não estava mais controlada pelos três ks - kinder, kürche e Kirche ${ }^{15}$ - passou a ser fonte de discussões, tipologias e categorizações. Segundo Lynne Frame (posição 217 de 3569), a República de Weimar foi acometida por uma mania de classificação - Furor des Rasterns - que surgiu como maneira de fornecer uma ordem simbólica ao caos econômico e social do período do pósguerra. A Neu Frau tem "os cabelos muito curtos $^{16}$ - - suas saias são mais curtas e cobrem a sua figura andrógina, ela é economicamente independente e sexualmente emancipada" (2013, p.2). A "masculinização" da mulher, conforme explica Katie Sutton (2011, p. ix) foi central para as representações das mudanças dos ideais de feminilidade no pós-guerra na Alemanha.

Os cabelos curtos, o monóculos, o smoking e as calças estão presentes em fotografias de diversas artistas de cabaré, tais como Marlene Dietrich e Anita Berber. Outras indumentárias que fizeram parte da estética cosmopolita conhecida como Garçonne-mode foram: chapéus de feltro, ternos, vestidos sem cintura marcada e sobretudos. Sutton (2011, p.1) aponta que "não foi acidente que o nunca visto nível de mobilidade política e social conquistado pelas alemãs no

${ }^{15}$ Filhos, cozinha e igreja.

${ }^{16}$ Conhecido na Alemanha como corte Bubikopf. No Brasil da década de 1920, graças ao Teatro de Revista, o corte ganhou o nome de À la Garçonne. 
início dos anos 1920 tenha encontrado sua representação visual na moda, já que esta é uma das mais óbvias formas de diferenciação de gênero". A moda, portanto, tornou-se foco da crítica social a respeito da modificação nos papéis de gênero.

Foi justamente performando uma canção sobre a nova moda feminina que a diseuse Margo Lion despontou em sua carreira e consolidou a sua persona como uma das representantes da Nova Mulher. Em 1921, acompanhada pelo letrista Marcellus Schiffer ${ }^{17}$, Lion fez o seu primeiro teste para cabaré, declamando o então poema satírico Die Linie der Mode. Em suas memórias, Trude Hesterberg recorda a primeira vez que viu Lion em cena durante um teste.

\begin{abstract}
Enquanto isso, a sombra longa e estreita de Lion já estava parada lá, me olhando de cima para baixo. "Você tem um figurino?" Eu perguntei. "Sim, aqui". Respondeu a sombra, tirando um maço de cigarro debaixo dos ombros longos. "Que?" Eu perguntei espantada. "Só isso?" - "É O bastante", ela disse feliz. Um tempo depois ela tomou o palco. Eu não queria acreditar no que estava vendo. Um longo pedaço de seda preto enrolava de forma apertada o corpo magro como uma régua. Preso apenas com alfinetes, a cauda do vestido se arrastava como um trem. $\mathrm{Na}$ cabeça, os cabelos estavam penteados para trás, decorados com uma caixa de medicamentos como chapéu. Os braços, excessivamente longos, terminavam nas mãos cobertas com duas luvas pretas curtas. 0 rosto estava pintado com uma maquiagem branca como giz, só era possível ver os olhos maquiados de preto e embaixo os lábios tingidos com batom preto. Uma imagem realmente grotesca e macabra. E então ela começou! Não é possível descrever de outra forma. [...]. Todas as vogais foram evidenciadas pelos movimentos dos braços, que lembravam uma cobra. Tudo isso junto exalava um tipo de perfume sexual. Era a expressão desses tempos mórbidos e exagerados: "Essa é o ponto de exclamação da miséria!" como disse o Marcellus Schiffer (Hesterberg apud Danielczyk, 2017, p.1).
\end{abstract}

Dois anos depois deste encontro, Margo Lion fez o seu debut no palco do Wilde Bühne apresentando a agora chanson, Die Linie der Mode, musicada por Mischa Spoliansky. A letra da música é uma crítica à nova forma da moda. Para além de uma oposição ao vestuário, é uma crítica ao corpo que não exibe mais marcadores de feminilidade e de maternidade, como curvas e seios sob decotes.

17 1892-1932. Autor, libretista e pintor que junto com o compositor Mischa Spoliansky foi responsável pela criação de diversas chansons de sucesso, como Die neuest Linie der Mode e Wenn die beste Freundin mit der besten Freundin. Com Spoliansky, escreveu também para o teatro de revista. Em 1928 casou-se com Margo Lion. 
Ela não tem quadril, ela não tem desejo/ Esse restolho de mulher!/ Ela abre os braços - ela gira em círculos/ O que ela quer?/ O que está de errado com ela?/ O que ela pode fazer?/ Quem sabe?/ Quem é esse ponto de exclamação da miséria?/ Uma mensageira da morte? Talvez seja a morte por inanição? Ou é a nova forma da moda? (Schiffer apud Danielczyk, 2017, p.147).

Sabine Hake (1997, posição 2893 de 3569) afirma que alguns termos passaram a definir a moda de acordo com termos de uso. Simplicidade, funcionalidade e versatilidade ditavam as escolhas. O corpo visto pela ótica do atleticismo tornou-se uma marca do corpo mecanizado. Hake ressalta que "o mito da instrumentalidade e do pragmatismo obsessivo também revela uma ansiedade contínua acerca das diferenças sexuais que não podiam ser aliviadas pelas promessas de libertação, igualdade e vestimenta casual" (idem). O visual mais andrógeno desafiava as noções tradicionais de beleza feminina. A sátira de Marcellus Schiffer em Die Linie der Mode desumaniza a mulher magra e sem curvas, associando-a à figura sobrenatural da morte. O letrista associa a falta de um quadril voluptuoso a uma ausência de desejo, o que a seu ver faz desta mulher apenas um restolho.

A Nova Mulher, enquanto um fenômeno de massa, tinha um enorme potencial de identificação. Margo Lion, uma mulher alta e magra, ciente da fisicalidade de seus longos braços, adotou o grotesco para fazer uma paródia física da canção de Schiffer. A diseuse ridicularizou os medos masculinos, colocandose como uma figura verdadeiramente sobrenatural, debochando da ironia utilizada pelo letrista ao associar a mulher com a morte. Segundo Sandra Danielczyk (2017, p.84), as personas de Lion estão sempre associadas ao discurso sobre feminilidade da República de Weimar. Ao invés de apenas levar esses tipos femininos para a cena, Lion criava versões grotescas deles. A performer se apropriou do tipo da Neurótica Urbana e o desenhou à sua maneira, sempre levando para a cena uma mulher que gradativamente vai ficando mais assustadora. Como afirmou Danielczyk (idem), Margo Lion mostrava a transformação do cisne em ganso.

Para Charlotte Fechner (2001, p.39), as imagens criadas pela canção de Marcellus Schiffer apresentam uma representação unilateral da mulher, que é a tipificação da Neurótica Urbana. Diretamente relacionada à vida na metrópole e ao 
fenômeno da Nova Mulher, a Neurótica Urbana é uma categoria mais ampla da qual derivam outras tipificações, tais como a anoréxica (representada na canção citada), a cleptomaníaca, a perversa e a nervosa. Evidenciam a relação da mulher com a cidade moderna, as relações de consumo, as ansiedades masculinas acerca dos papéis de gênero. Rüdiger Graf (2009, p.648) afirma que havia, na época, uma associação entre as discussões acerca da modernidade e os debates sobre o fenômeno da Nova Mulher. De acordo com Kattie Sutton (2011, p.xiii), tal associação estava relacionada ao fato desta ser entendida como um símbolo de transformação e ruptura, já que representava a crise nos papéis de gênero, o que por sua vez era uma resposta ao "choque da modernidade".

Os debates acerca dos impactos da vida na cidade também tangenciaram a tipificação da Prostituta. O processo de industrialização de Berlim foi vertiginoso, o que atraiu grandes levas migratórias. Ao final do século XIX era a maior cidade industrial da Europa, conforme afirma Lionel Richard (1993, p.14). Exemplo de megalópole moderna, na década de 1920 a cidade contava com um complexo industrial diversificado, rede ferroviária bem desenvolvida, um aeroporto, universidades de prestígio e muito entretenimento noturno. Para George Simmel (1973, p.16) a modernidade pode ser representada por dois símbolos, que juntos produzem o singular modo de vida moderno: a metrópole e o dinheiro. Esta junção gerou uma objetivação e uma instrumentalização das relações sociais. A modernidade em Berlim, segundo Richard (1993, p.15), teve a sua faceta obscura: "o movimento incessante, o burburinho, o anonimato, a solidão, a corrupção, a prostituição" (Richard,1993, p.15).

Durante os primeiros anos da República de Weimar, Berlim se consolidou como a capital do turismo sexual. Assolada por uma hiperinflação, a moeda alemã enfrentou uma imensa desvalorização, chegando à equiparação de 1 dólar para 4.2 trilhões de marcos. A bem da verdade, a prostituição já era tema de calorosos debates, inclusive pelo movimento de mulheres, desde o século XIX. Foi na década de 1920, no entanto, que o Furor des Rasterns culminou na catalogação da prática. De acordo com Mel Gordon (2006, p.36) a cidade estava dividida em doze zonas de prostituição e os trabalhadores eram divididos em categorias de acordo com especialidade e local de trabalho, que variava entre hotéis, bares, cafés, bordéis, 
parques, becos, ruas, estações de trem e pequenos cabarés.

Desde os primórdios do cabaré em Montmartre, a chanson de cabaré levou para cena os marginalizados. Aristide Bruant cantou as prostitutas e os prisioneiros em suas canções de cunho social. Nascia ali, o que, posteriormente, os alemães chamariam de Dirnenlied. Para Ruttkowski (2001, p.56) as canções de prostituta são o mais proeminente subgênero das chansons cabareteiras. Se no cabaré de fin de siecle as Dirnenlieden traziam retratos ultra romantizados do submundo ou relatos depressivos acerca do destino das prostitutas, os cabarés literários da República de Weimar trouxeram algumas abordagens não convencionais.

Segundo Jill Smith (2014, posição 3434 de 6005), Valeska Gert, bailarina grotesca e atriz anárquica, inovou ao retratar em cena a sexualidade da prostituta, criando assim a Dirnentanz, dança na prostituta. Gert mostrava a virilha, rebolava e fazia gestos provocativos para o público. Para Smith (2014, posição 3434 de 6005) "ao dar à sua audiência uma versão mais extrema do que daquilo que eles sorrateiramente queriam, Gert confrontava os espectadores com seus próprios desejos sexuais, fazendo com que se encolhessem nas cadeiras". Ao invés de retratar a sexualidade da prostituta como desviante, Gert mostrava que aquele tipo de sexualidade negada pela burguesia é também seu objeto de desejo. Nessa Dirnentanz a sexualidade da prostituta atende, primeiramente, a ela mesma, deixando o cliente/espectador em segundo plano. As escolhas da performer trouxeram para cena uma abordagem original e menos convencional.

Em O Anjo Azul, o professor Imannuel Rath se apaixona por Lola-Lola, personagem de Marlene Dietrich, ao vê-la interpretando a Dirnenlied Falling in love again. Composta por Friedrich Hollaender, as passagens da letra indicam uma prostituta para quem o amor é um negócio - "o amor sempre foi meu jogo e eu jogo como posso" - e apesar de não querer se apaixonar, ela não pode evitar já que "fui feita deste jeito". Charlotte Fechner aponta que:

Por um lado, naquele contexto, Lola-Lola simboliza a mais comum das apresentações cabareteiras da prostituta: a femme fatale, sedutora, que usa a sua sexualidade feminina. Por outro lado, ela é apresentada como vítima desta sexualidade por não conseguir se conter (Fechner, 2001, p.42). 
As canções de prostituta atingiram o pico de sua popularidade em Berlim durante os primeiros anos da República de Weimar, coincidindo com o período no qual as discussões acerca da Nova Mulher estavam mais em voga. A partir da metade da década, as Dirnenlieden perderam força. O sub gênero de canção passou por um rápido revival com a estreia, em 1928, da Ópera dos três vinténs de Bertolt Brecht e Kurt Weil, por conta da personagem Jenny. Na peça, Brecht apresenta o paradoxo inerente da prostituta, uma figura que ao mesmo tempo afirma e subverte as estruturas sociais. Katrin Sieg (1997, p.67) apresenta um paradoxo parecido a respeito da presença e da força das mulheres no cabaré. Para a autora, o tanto a chanson quanto o número de dança exibem uma atração pelas tradições populares que, em conjunto com as forças mercadológicas, colabora para a comodificação e a sexualização das mulheres, ao mesmo tempo em que são um local importante de intervenção feminista.

\section{Conclusão}

O cabaré é um gênero que existe em processo e opera na base da contradição, equilibrando-se entre a experimentação artística, o entretenimento de massa e a agitação política. Ao propor-se comentar a atualidade em tempo real, acompanha de maneira imediata as tendências, as vivências e os debates. Desprovido da distância histórica que só o futuro oferece, o cabaré está imerso nas angústias e ansiedades de sua época. De seu lugar paradoxal, apresenta uma lógica de apresentação, apropriação, rebelião e negociação, nesta ordem.

A República de Weimar foi um período complexo, contraditório e intenso. A mulher ocupava um espaço no centro desta contradição. Os recém adquiridos direitos à participação política, o ingresso no mercado de trabalho, a nova abordagem ao corpo, a existência possível para além espaço doméstico, a cultura do lazer e do consumo contribuíram para a construção da imagem poderosa da Nova Mulher. Ícone da independência econômica e sexual, esta mulher autoconfiante foi vista como uma ameaça à estabilidade social e à reconstrução econômica e política da Alemanha.

Corporificações do fenômeno da Nova Mulher, as artistas aqui estudadas, em 
especial Margo Lion, Valeska Gert e Marlene Dietrich, foram fundamentais para as discussões acerca dos papéis de gênero. A partir de decisões artísticas conscientes, elas parodiaram a sátira masculina, subvertendo as tipificações sociais e apresentaram alternativas possíveis para a presença de mulheres na cena. Suas investigações cênicas trouxeram contribuições relevantes para a arte da Diseuse e para a dança grotesca. Com a criação de suas máscaras-rituais e personas, ampliaram as possibilidades de criação feminina, mantendo a porta aberta para a comédia, o grotesco, a paródia, o deboche e a fúria. Emprestaram à musa do cabaré a sua característica mais essencial: a desobediência.

\section{Referências}

ANKUM, K. VON (org). Women in the metropolis: gender and modernity in Weimar culture. Berkeley: University of California Press, 1997. kindle edition

APPIGNANESI, Lisa. Cabaret the first hundred years. London: Methuen, 1984.

BAILEY, Peter. Conspiracies of Meaning: Music-Hall and the Knowingness of Popular Culture. The past and present society magazine. No. 144 (Aug, 1994), p. 138-170.

BOAK, Helen. Women in the Weimar Republic. Manchester: Manchester University Press, 2013.

BRECHT, Bertolt. The Messingkauf Dialogues. London: Methuen, 1994.

COHEN, Renato. Performance como linguagem: criação de um tempo-espaço de experimentação. São Paulo: Perspectiva, 2002.

DANIELCZYK, Sandra. Diseusen in der Weimarer Republik. Imagekonstruktionen im Kabarett am Beispiel von Margo Lion und Blandine Ebinger. Bielefeld: Transcript verlag, 2017.

DOUBLE, Oliver; Wilson, Michael. Brecht and Cabaret. In: THOMPSON, Peter; SACKS, Glendyr. The Cambridge Companion to Brecht. Cambridge: Cambridge University Press, 2006.

FARINA, Willian. The German cabaret legacy in American popular music. Jefferson: McFarland \& Company, Inc, 2013.

FECHNER, Charlotte. The Berlin Cabaret \& the Neue Frau 1918-1933. München: GRIN verlag, 2001. 
FERRAN. Peter Wigglesworth. The Threepenny Songs: Cabaret and the Lyrical Gestus. Theater, Volume 30, Number 3, Fall 2000, pp. 5-21

GILL, Anton. Dance Between Flames: Berlin Between the Wars. Londres: Endeavour Press, 2015. Kindle Edition.

GORDON, Mel. Voluptuous panic: the erotic world of Weimar Berlin. Los Angeles: Feral House, 2006

GRAF, Rüdiger. Anticipating the Future in the Present: "New Women" and Other Beings of the Future in Weimar Germany. Central European History, vol. 42, no. 4, p. 647-673, 2009.

HAKE, Sabine. In the mirror of fashion. In: ANKUM, Katherine von (org). Women in the metropolis: gender and modernity in Weimar culture. Berkeley: University of California Press, 1997. kindle edition

LEWIS, Beth Irwin. Lustmord: inside the Windows of the Metropolis. In: ANKUM, Katherine von (org). Women in the metropolis: gender and modernity in Weimar culture. Berkeley: University of California Press, 1997. kindle edition

MAFESSOLI, Michel. O imaginário é uma realidade. Revista FAMECOS, Porto Alegre, no 15, p.74-83, agosto, 2001.

MIZEJEWSKI, Linda. Divine Decadence: Fascism, Female Spectacle, and the Makings of Sally Bowles. Princeton: Princeton University Press, 2014, p.44

PAVIS, Patrice. Dicionário de Teatro. São Paulo: Perspectiva, 2008.

RICHARD, Lionel. Berlim, 1919-1933. a encarnação extrema da modernidade. Rio de Janeiro: J. Zahar, 1993.

RICHIE, Alexandra. Faust's Metropolis: a history of Berlin. London: William Collins, 2013. Kindle Edition.

RUTTKOWSKI, Wolfgang. Cabaret Songs. Popular Music \& Society, 25:3-4, 45-71, 2001.

SCHASER, Angelika. Gendered Germany. In: RETALLACK, J. N. (ED.). Imperial Germany, 1871-1918. New York: Oxford University Press, 2008.

SCHMID, Carol. The 'New Woman' Gender Roles and Urban Modernism in Interwar Berlin and Shanghai. Journal of International Women's Studies, 15(1), 1-1, 2014.

SIEG. Katrin. Exiles, Eccentrics, Activists: Women in Contemporary German Theater. Ann Harbor: The University of Michigan Press, 1997.

SIMMEL, George. A Metrópole e a Vida Mental. In: VELHO, Otávio G (org.). O Fenômeno Urbano. Rio de Janeiro: Ed. Guanabara, 1973. 
STREVA, Christina. Por um ator-provocador e um professor-criador. uma pesquisaação sobre a performance de cabaré. Tese (Doutorado) - Universidade Federal do Estado do Rio de Janeiro, Rio de Janeiro, 2017.

SUTTON, Katie. The Masculine Woman in Weimar Germany. New York: Berghahn Books, 2011.

TURNER, Victor. O processo ritual: estrutura e antiestrutura. Petrópolis: Vozes, 2013. WIDDIG, Bernd. Culture and inflation in Weimar Germany. Berkeley: University of California Press, 2001.

Recebido em: 20/06/2021

Aprovado em: 12/08/2021 